\title{
Article \\ A Method for the Design of Concrete with Combined Steel and Basalt Fiber
}

\author{
Leonid Dvorkin $^{1}$, Oleh Bordiuzhenko ${ }^{1}(\mathbb{D})$, Biruk Hailu Tekle ${ }^{2}$ (D) and Yuri Ribakov ${ }^{3, *(D)}$ \\ 1 Department of Building Elements, Technology and Materials Science, National University of Water and \\ Environmental Engineering, 33028 Rivne, Ukraine; dvorkin.leonid@gmail.com (L.D.); \\ o.m.bordiuzhenko@nuwm.edu.ua (O.B.) \\ 2 Structural Concrete Institute, Leipzig University of Applied Sciences (HTWK Leipzig), \\ 04277 Leipzig, Germany; birukh.tekle@gmail.com \\ 3 Department of Civil Engineering, Ariel University, Ariel 40700, Israel \\ * Correspondence: ribakov@ariel.ac.il
}

Citation: Dvorkin, L.; Bordiuzhenko, O.; Tekle, B.H.; Ribakov, Y. A Method for the Design of Concrete with Combined Steel and Basalt Fiber. Appl. Sci. 2021, 11, 8850. https:// doi.org/10.3390/app11198850

Academic Editors: Alexey Beskopylny and Anatoly Lavrentyev

Received: 11 August 2021

Accepted: 18 September 2021

Published: 23 September 2021

Publisher's Note: MDPI stays neutral with regard to jurisdictional claims in published maps and institutional affiliations.

Copyright: (c) 2021 by the authors. Licensee MDPI, Basel, Switzerland This article is an open access article distributed under the terms and conditions of the Creative Commons Attribution (CC BY) license (https:// creativecommons.org/licenses/by/ $4.0 /)$.

\begin{abstract}
Combining different fiber types may improve the mechanical properties of fiber reinforced concrete. The present study is focused on investigating hybrid fiber reinforced concrete (HFRC) with steel and basalt fiber. Mechanical properties of fiber reinforced fine-grained concrete are investigated. The results demonstrate that using optimal steel and basalt fiber reinforcement ratios avoids concrete mixtures' segregation and improves their homogeneity. Concrete with hybrid steel and basalt fiber reinforcement has higher strength. Effective methodology for proper design of HFRC compositions was proposed. It is based on the mathematical experiments planning method. The proposed method enables optimal mix proportioning of high-strength fine-grained concrete with hybrid steel and basalt fiber reinforcement.
\end{abstract}

Keywords: hybrid fiber reinforced concrete; steel fiber; basalt fiber; polypropylene fiber; concrete strength; composition design

\section{Introduction}

Steel fiber reinforced high-strength concrete (SFRHSC) became a widely used material for structural engineering applications. Many studies were carried out to investigate its properties. New design methods were proposed for providing its ductile behavior and limit its crack development [1]. The studies in fiber reinforced concrete are mainly focused on investigating its mechanical properties such as compressive strength, split tensile strength, toughness, modulus of rupture, post-cracking performance, modulus of elasticity, Poisson's ratio and strain at peak compressive stress [2-4]. Experimental results from these studies show that fiber reinforced concrete has better post-cracking behavior and more ductility for different fiber types.

Sahin and Koksal investigated the influence of steel fiber's tensile strength on the mechanical properties of fiber reinforced concrete [5]. Fiber with tensile strengths of 1100 and $2000 \mathrm{MPa}$ was used. Steel fiber contents of $0.33 \%, 0.67 \%$ and $1 \%$ were used. The concrete mix water/cement ratios were $0.35,0.45$ and 0.55 . The results showed the significant effect of the matrix and fiber strength on the fracture energy and characteristic length. Hence the authors recommended taking these parameters into account as criteria in addition to other parameters such as volume fraction and aspect ratio. Suksawang N [6] studied the influence of steel, basalt and other types of fiber on the modulus of elasticity of concrete and cement composites. The results showed that fiber has negligible influence on the modulus of elasticity if the coarse-to-fine aggregate ratio is higher than 1; otherwise discrete fiber reduces the modulus of elasticity. A new equation was proposed for estimating fiber reinforced concrete's modulus of elasticity. The equation is valid for a maximum fiber content of $10 \%$ by volume. It was demonstrated that the equation 
allows accurate prediction of fiber reinforced concrete and cement composites modulus of elasticity values.

Due to its considerable advantages, SFRHSC has different application prospects. For instance, replacing normal-strength concrete with SFRHSC results in effective and cheaper solutions suitable for new structures and retrofitting existing ones [7,8]. For instance, twolayer beams, consisting of SFRHSC in the compression zone and normal strength concrete in the tension zone, are effective bending elements $[7,8]$. Using such beams is logical because as their span becomes longer and the service load increases, a higher concrete strength is required in the compression zone to withstand rather large bending moments.

Steel fibers are prone to corrosion and their higher density can be a limitation on their use. Fibers such as basalt fiber (BF) can be a better alternative in such cases. Basalt fiber (BF) production could be arranged at low costs for any business needs [9]. Following the obtained data, even low contents of BF yield an increase in flexural strength of the tested specimens. It was also reported that using BF reinforced concrete is less costly compared to steel, s-glass or carbon fibers. Ayub et al. investigated the influences of adding 1, 2 and $3 \%$ of BF in high-performance concrete (HPC) [10]. One mix was prepared by using $100 \%$ cement, and the other two mixes by replacing $10 \%$ cement content with silica fume and metakaolin. It was concluded that adding $2 \%$ of BF by volume together with mineral admixtures improved the concrete compressive strength. Additionally, improved strains at maximum compressive strength and splitting tensile strength were observed. Ayub et al. investigated compressive stress-strain behavior of fiber reinforced HSC with compressive strengths of 70-85 MPa, and BF content of 1-3\% [11]. Based on the experimental data, an analytical model of such concrete stress-strain behavior was proposed. The model has demonstrated good agreement with the experimental data.

Comparative effect of basalt and steel fiber on compressive, flexural and splitting tensile strength of concrete class $\mathrm{C} 30 / 37$ was studied [12]. It was reported that the optimum content of BF and steel fiber (SF) for concrete class $\mathrm{C} 30 / 37$ is $0.75 \%$ and $0.5 \%$ by volume, respectively. The increase in concrete compressive strength with optimum $\mathrm{BF}$ was $9.3 \%$ and for SF $11.9 \%$. The increase in splitting tensile strength of concrete was $43 \%$ and $48 \%$, correspondingly. BF increased flexural concrete strength by $9.5 \%$ and SF by $12.5 \%$. It was concluded that concrete with SF is better overall compared to that with BF. However, the authors believe that adding $0.75 \%$ of $\mathrm{BF}$ could be problematic from the viewpoint of uniform SF distribution in concrete. Kumar et al. investigated mechanical properties and technological and application aspects of BF and SF in C40 grade concrete [13]. Beams, cubic and cylindrical specimens with $0 \%, 0.25 \%, 0.5 \%, 0.75 \%, 1 \%$ and $1.25 \%$ of fiber were tested. The relationship between compressive, flexural and tensile strength at 7 and 28 days was obtained. The results show that compressive strengths at $1 \%$ and $1.25 \%$ of $\mathrm{BF}$ and $\mathrm{SF}$ are lower compared to normal cement concrete. Splitting tensile and flexural strengths become lower at $1.25 \%$ of BF and SF. The concrete with BF performed better than the SF counterpart in terms of compressive, flexural and splitting tensile strengths.

Shaikh and Taweel [14] studied the effect of elevated temperature on SF and BF reinforced concretes. Both types of fibers reduced spalling and explosive failures. Manu, Eldhose [15] performed a study on the toughness, flexural strength and load-deflection behavior of concrete beams with hybrid BF and SF reinforcement. Different fiber content and aspect ratio were selected. Reinforced concrete beams with SF and BF were cast for comparison. The ultimate load in beams with hybrid fiber content of $2 \%$ is $25 \%$ higher, compared to those without fibers. From the viewpoint of ultimate load, hybrid fiber reinforcement was more effective compared to single BF or SF by $20 \%$ and $9 \%$, respectively. Beams with hybrid fiber exhibited higher deflections relative to specimens with single SF or BF. Specimens with single BF reinforcement demonstrated lower energy absorption, compared to hybrid fiber reinforced beams. These positive features were achieved because hybrid fiber has higher crack bridging effect compared to single SF or BF. Li et al. [16] studied the effect of hybrid fiber content on the shear strength, toughness, flexural strength 
and residual load capacity. The best shear strength and toughness were obtained at $180 \mathrm{~kg} / \mathrm{m}^{3}$ of SF and $4.5 \mathrm{~kg} / \mathrm{m}^{3} \mathrm{BF}$.

It is evident that concrete with hybrid fiber has better performance. SF makes significant improvements on the mechanical behavior of concrete by controlling the cracking and improving the flexural strength and toughness. BF which has high resistance to radiation and oxidation and improved fracture energy and abrasion resistance leads to increased flexural strength [17]. Synthetic fiber types such as polypropylene fiber (PF) are resistant to chemicals and are capable of arresting micro crack growths. They are effective in reducing plastic shrinkage cracks and can be used in different harsh environments.

More research on the mechanical properties of high-performance concrete with hybrid fiber reinforcement is required, as experimental data reported in the literature is limited. In most cases, the available data are focused on concrete classes with compressive strength up to $50 \mathrm{MPa}$. The present research is focused on investigating the effect of hybrid SF and $\mathrm{BF}$ and concrete mix composition on high-performance concrete strength. Such concrete has application prospects in areas requiring high strength concretes with improved postcracking behavior.

\section{Research Aims, Scope and Novelty}

A review of recent publications show high interest in the mechanical properties of concrete with hybrid SF and BF reinforcement. Following the available data, a common effect of both fiber types yield essential improvement in the mechanical properties of concrete. However, the design of such concrete compositions is mainly based on engineering experience. Therefore, an effective methodology for effective design of hybrid fiber reinforced concrete (HFRC) mix composition should be developed.

It is demonstrated that optimal design of high-performance concrete with hybrid SF and $\mathrm{BF}$ can be carried out using adapted mathematical experiments planning methods. The main novelty of the research is verifying the effect of adding hybrid fiber reinforcement for improving the homogeneity of fine-grained fiber reinforced concrete mixtures and preventing their segregation. It yields higher values of hardened concrete strength. The study presents a methodology for the design of HFRC compositions based on the adapted mathematical experiments planning method.

\section{Experimental Program}

\subsection{Concrete Composition and Mix Preparation Technology}

Series of HFRC specimens were prepared using SF, BF and PF fibers. Table 1 shows the composition of fine-grained concrete is used.

Table 1. Concrete mix proportion.

\begin{tabular}{cc}
\hline Ingredients & Amount $\mathbf{( k g / \mathbf { m } ^ { 3 } )}$ \\
\hline Portland cement CEM 42.5 & 500 \\
Water & 175 \\
Sand (2-5 mm) & 990 \\
SF & 810 \\
BF & 80 and 120 \\
PF & 0 to 6 \\
Fine sand (fineness modulus of 2.1$)$ & 0 to 2 \\
Melflux 2651F superplasticizer & Varied to achieve $13-15 \mathrm{~cm}$ slump \\
\hline
\end{tabular}

The sand grading curve is shown in Figure 1. The shape of corrugated SF is shown in Figure 2. The normative tensile strength of the $\mathrm{SF}$ was $1335 \mathrm{MPa}$. The steel fiber dimensions are as follows: $50.0 \pm 5.0 \mathrm{~mm}$ length; $1.0 \pm 0.1 \mathrm{~mm}$ thickness and of $5.0 \pm 0.1 \mathrm{~mm}$ wave width [18]. The lengths of BF were 12 and $24 \mathrm{~mm}$ with $16 \mu \mathrm{m}$ diameter. The lengths of the 
PF were 12 and $18 \mathrm{~mm}$ with 20-33 $\mu \mathrm{m}$ diameter. The BF has a tensile strength of $2.8 \mathrm{GPa}$ and modulus of elasticity of $85 \mathrm{GPa}$, while the PF has a $400 \mathrm{MPa}$ and $4 \mathrm{GPa}$, respectively.

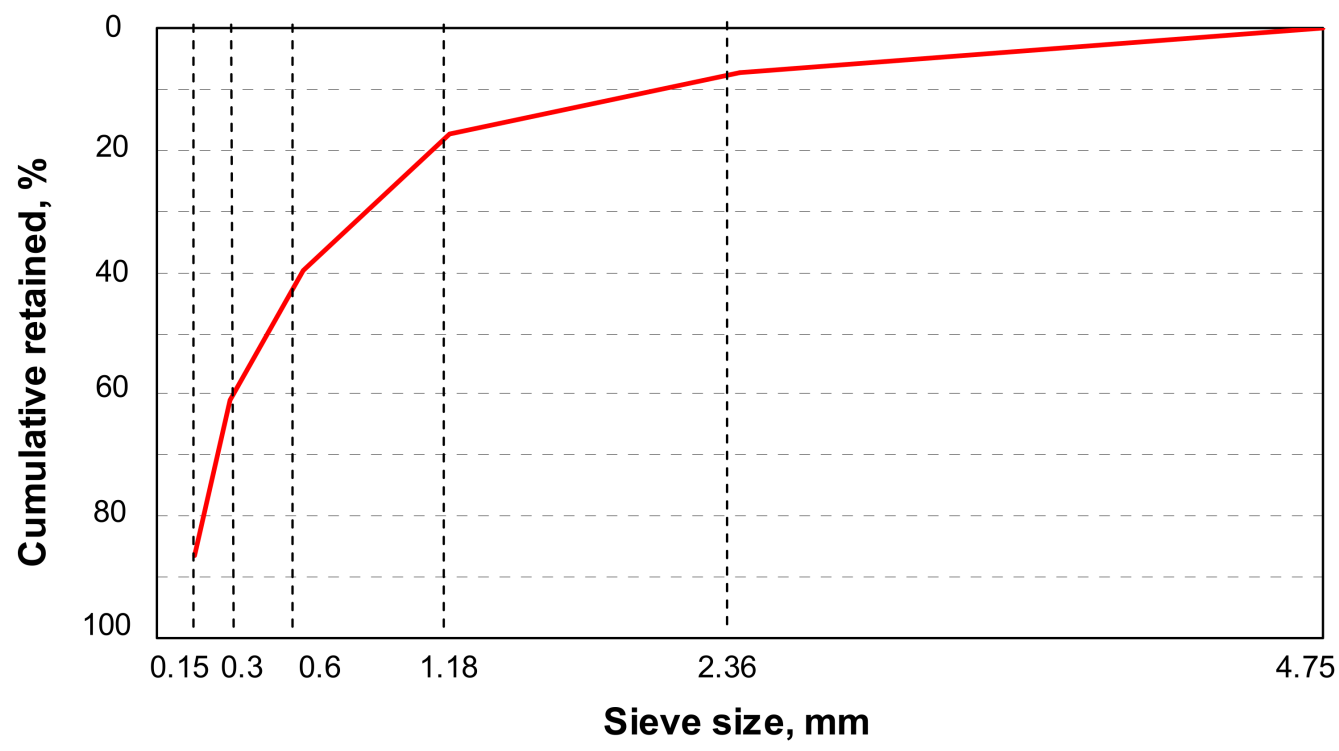

Figure 1. Grading curve of sand.

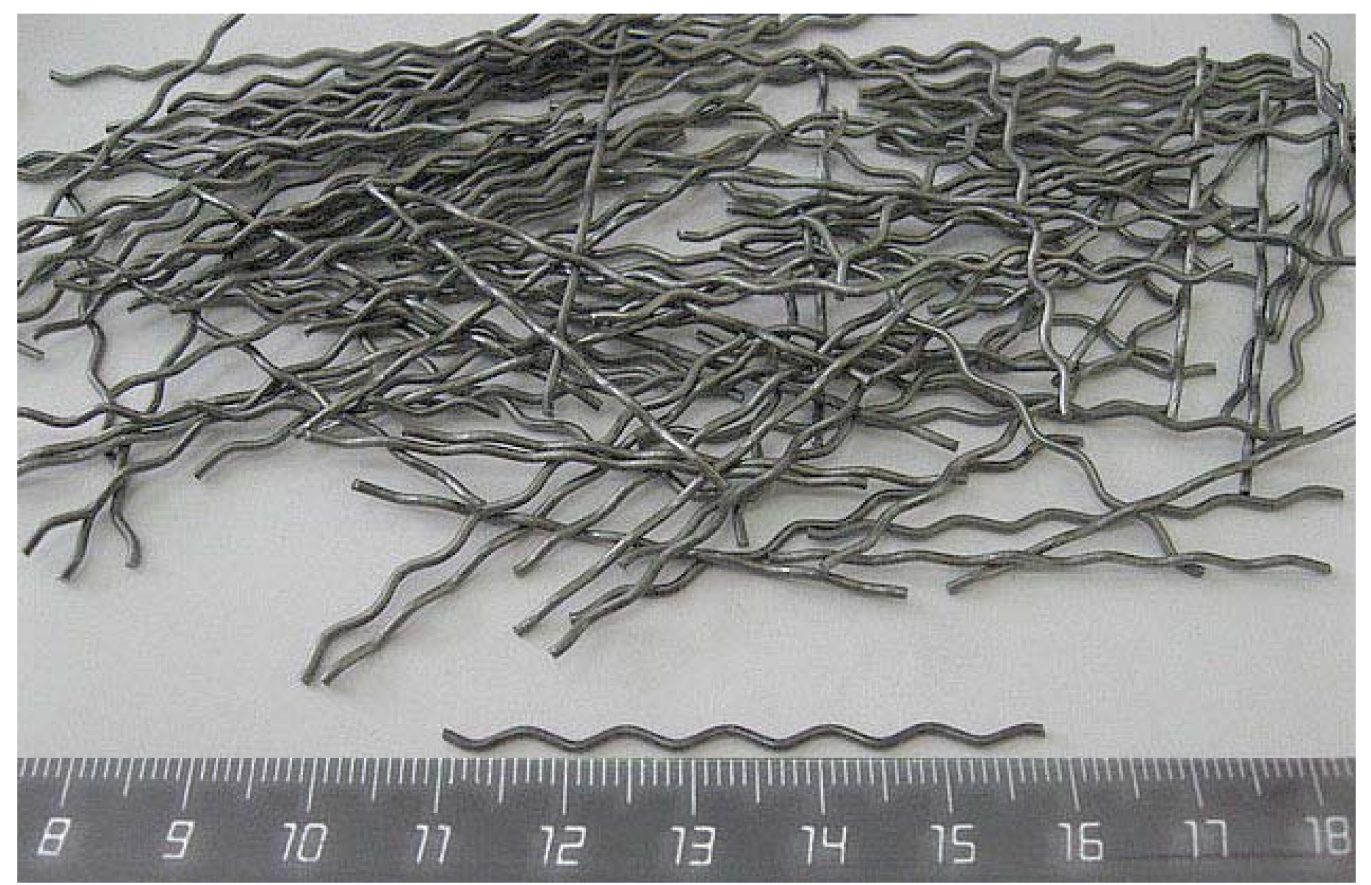

Figure 2. Steel fiber used in the research.

Production of HFRC has included adding BF or PF to the superplasticizer and mixing for about $40-60 \mathrm{~s}$ by a laboratory mixer. The fibers were added in a small amount to avoid fiber balling and produce concrete with uniform materials consistency. After that, cement was added to the loosed fiber and mixing continued until a homogenous suspension was obtained. At the following stage, the aggregate was added in the suspension followed by SF while continuously mixing. Following such technology avoids fiber clumping and enables obtaining a concrete mix with necessary homogeneity. 


\subsection{Tested Specimens, Equipment and Procedure}

For casting the concrete specimens, standard molds were used. The specimens were compacted on a vibration table. After $24 \mathrm{~h}$ of normal hardening, the specimens were kept in the environmental control room (relative humidity of over $90 \%$ and temperature of $18 \pm 2{ }^{\circ} \mathrm{C}$ ) until the test day.

A hydraulic testing machine with load capacity of $1000 \mathrm{kN}$ was used to carry out the compressive strength tests. The applied load rate was $0.3 \mathrm{kN} / \mathrm{s}$. Nine cubic specimens $(100 \times 100 \times 100 \mathrm{~mm})$ were tested: three at 1 day, three at 7 days and three at 28 days.

In order to obtain the flexural strength, $70 \times 70 \times 280 \mathrm{~mm}$ specimens were tested at 1 , 7 and 28 days. For each concrete composition, three specimens were tested. The applied load had a constant rate of $0.05 \mathrm{MPa} / \mathrm{s}$. The machine for testing flexural strength has four rollers. Following [19], the distance between the two upper rollers was equal to the specimen depth, and that between the two bottom ones equals thrice the specimen depth.

\subsection{Experiments Planning Using Regression Modeling}

Experimental data, obtained at the preliminary research stage, were processed statistically. Corresponding experimental-statistical models were obtained for properties of the investigated fiber reinforced concrete with hybrid fiber reinforcement. Such models allow considering the main factors' influence on the obtained properties. In most cases, these models have a form of second-order polynomial equations:

$$
\hat{y}=b_{0}+\sum_{i=1}^{k} b_{i} x_{i}+\sum_{i=1}^{k} b_{i i} x_{i}^{2}+\sum_{i\langle j} b_{i j} x_{i} x_{j}
$$

where $y$ is the investigated parameter; $b_{0}, b_{i}, b_{i i}, b_{i j}$ are the regression coefficients; $x_{i}, x_{i i}$, $x_{i j}$ are the investigated factors and $k$ is the factors' number. The values of the regression coefficients provide information on the effect of corresponding factors on the investigated feature or parameter.

In the present study, a three-level four-factor $\mathrm{B}_{4}$-type plan was used [20] because it allows proper consideration of mix composition factors' effect on fiber reinforced concrete strength characteristics. Experimental data, obtained from the testing at 1, 7 and 28 days, were processed to calculate the corresponding regression coefficients. Consequently, dependences for fiber reinforced concrete strength were obtained in the form of Equation (1). Based on the regression equations, corresponding graphs of concrete strength characteristics vs. the investigated influence factors were obtained. The mathematical models and graphs were used to analyze the research results and develop a method for design compositions of HFRC.

\section{Experimental Results}

A preliminary investigation was first carried out to study the optimal contents of $\mathrm{SF}, \mathrm{BF}$ and $\mathrm{PF}$, as well as to investigate, which of the $\mathrm{SF}+\mathrm{BF}$ and $\mathrm{SF}+\mathrm{PF}$ combinations is preferable. At this stage fiber reinforced concrete properties were obtained at 7 days only to save the manpower resources. Based on the preliminary results, the influence of water-cement ratio, cement content and the investigated fiber type content on strength properties of HFRC was studied. With this aim, a three-level four-factor experiment plan was realized $[20,21]$. According to the plan, three specimens were tested, as was mentioned above, for each concrete composition at 1,7 and 28 days.

\subsection{Influence of Steel and Basalt Fiber Contents on Concrete Strength}

The values of HFRC strength at 7 days for different combinations of SF and BF are presented in Table 2. As it follows from this table, adding BF has a mainly positive effect in terms of flexural tensile strength up to a certain fiber dosage. For instance, the flexural strength for control concrete specimens with $\mathrm{SF}$ content of $80 \mathrm{~kg} / \mathrm{m}^{3}$ is $10.3 \mathrm{MPa}$, whereas 
for specimens with hybrid SF and BF reinforcement is $12.4 \mathrm{MPa}$ (for $4 \mathrm{~kg} / \mathrm{m}^{3}$ of $12 \mathrm{~mm} \mathrm{BF}$ ).

The average increase in flexural tensile strength is from $7 \%$ to $20 \%$.

Table 2. Strength of concrete specimens with different SF and BF contents.

\begin{tabular}{|c|c|c|c|c|c|}
\hline $\mathrm{SF}, \mathrm{kg} / \mathrm{m}^{3}$ & $\mathrm{BF}, \mathrm{kg} / \mathrm{m}^{3}$ & $\begin{array}{c}\text { Total Fibers } \\
\text { Content by Volume, } \\
\mu, \%\end{array}$ & $\begin{array}{l}\text { BF Part in the } \\
\text { Fiber Volume, } \\
n\end{array}$ & $\begin{array}{c}\text { Compressive } \\
\text { Strength at } 7 \text { Days } \\
f_{c m}{ }^{7} \\
\mathrm{MPa}\end{array}$ & $\begin{array}{c}\text { Flexural Tensile } \\
\text { Strength at } 7 \text { Days } \\
f_{c, t f}{ }^{7} \\
\text { MPa }\end{array}$ \\
\hline \multicolumn{6}{|c|}{$\mathrm{BF}(l=12 \mathrm{~mm})$} \\
\hline \multirow{4}{*}{80} & 0 & 1.03 & 0.00 & 64.5 & 10.3 \\
\hline & 2 & 1.10 & 0.07 & 65.2 & 12.1 \\
\hline & 4 & 1.18 & 0.13 & 67.1 & 12.4 \\
\hline & 6 & 1.25 & 0.18 & 66.2 & 10.2 \\
\hline \multirow{4}{*}{120} & 0 & 1.54 & 0.00 & 66.8 & 13.3 \\
\hline & 2 & 1.61 & 0.05 & 66.5 & 14.8 \\
\hline & 4 & 1.69 & 0.09 & 69.2 & 14.9 \\
\hline & 6 & 1.76 & 0.13 & 65.4 & 11.5 \\
\hline \multicolumn{6}{|c|}{$\mathrm{BF}(l=24 \mathrm{~mm})$} \\
\hline \multirow{4}{*}{80} & 0 & 1.03 & 0.00 & 64.5 & 10.3 \\
\hline & 2 & 1.10 & 0.07 & 67.2 & 11.0 \\
\hline & 4 & 1.18 & 0.13 & 63.1 & 9.6 \\
\hline & 6 & 1.25 & 0.18 & 62.8 & 6.5 \\
\hline \multirow{4}{*}{120} & 0 & 1.54 & 0.00 & 66.8 & 13.3 \\
\hline & 2 & 1.61 & 0.05 & 68.6 & 13.5 \\
\hline & 4 & 1.69 & 0.09 & 63.1 & 11.9 \\
\hline & 6 & 1.76 & 0.13 & 61.7 & 7.9 \\
\hline
\end{tabular}

The flexural strength for control concrete specimens with SF content of $120 \mathrm{~kg} / \mathrm{m}^{3}$ is 13.3 MPa, and its maximum value for hybrid SF and BF is $14.9 \mathrm{MPa}$ (for $4 \mathrm{~kg} / \mathrm{m}^{3}$ of $12 \mathrm{~mm}$ $\mathrm{BF})$. Thus, the maximum increase in strength is $12 \%$. The lower effect, in this case, could be due to the attainment of the maximum possible fiber content by volume.

Using BF with a length of $24 \mathrm{~mm}$ has demonstrated a relatively lower performance. The flexural strength increase was just by $7 \%$ at BF content of $2 \mathrm{~kg} / \mathrm{m}^{3}$ at SF content of $80 \mathrm{~kg} / \mathrm{m}^{3}$. Further increase in the BF content yielded a maximum decrease in flexural strength up to $40 \%$. Han et al. [22] observed that flexural strength increases with the increase of fiber length to a maximum aggregate size ratio of up to about 3 and gradually decreases after that. For the $24 \mathrm{~mm} \mathrm{BF}$ in the current study this ratio is close to 5 . The fiber length initially has a positive effect due to the bridging effect of the fibers. However, when the length exceeds the optimum value, the fibers tend to bend during mixing reducing the effective length of the fiber and in turn reducing its reinforcing effect. Additionally, longer fibers tend to have less distribution in the fiber reinforced concrete that has a further effect on concrete structure.

As shown in Figure 3, the optimum fiber content for the $12 \mathrm{~mm} \mathrm{BF}$ is 2 to $4 \mathrm{~kg} / \mathrm{m}^{3}$ at both dosages of SF. For the $24 \mathrm{~mm} \mathrm{BF}$ the optimum BF content is $2 \mathrm{~kg} / \mathrm{m}^{3}$ at both SF dosages. Higher BF content yields an increase of the dispersed reinforcement specific area, increasing the water-cement ratio, required to achieve the necessary workability. As expected, the compressive strength of HFRC is almost independent of the BF content (see Table 2). 


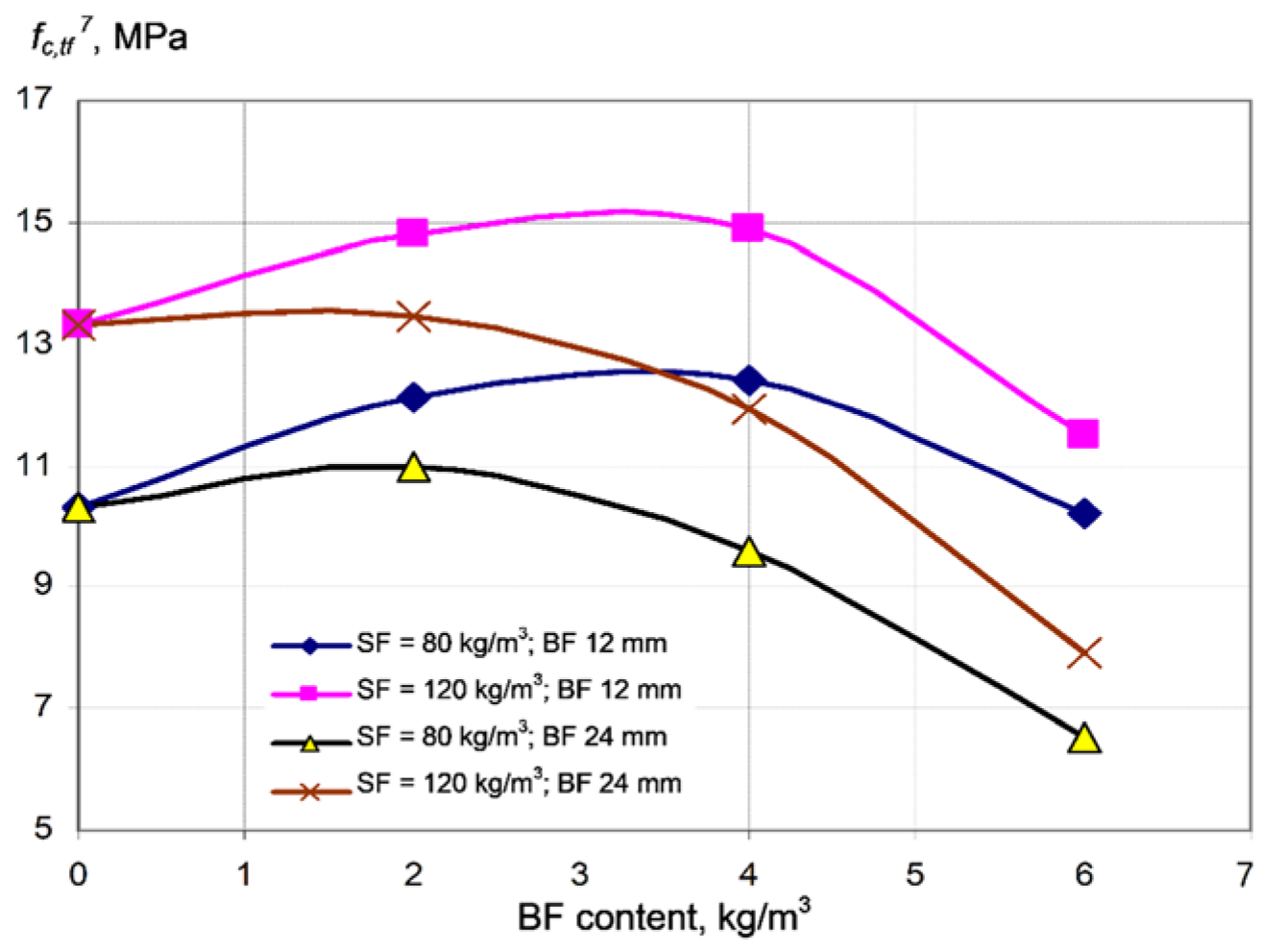

Figure 3. Dependence of flexural tensile strength at 7 days vs. BF length, SF and BF contents.

\subsection{Influence of Steel and Polypropylene Fiber Contents on Concrete Strength}

Using PF, which is a low modulus fiber, yields almost the same compressive strength and decreases the flexural tensile strength 5 to $40 \%$, compared to the control specimens. Results, presented in Table 3, demonstrate that using PF as a component of composite reinforcement yields a lower effect, compared to BF. It is explained, first of all, by worse PF distribution in concrete structure, which avoids a uniform distribution of SF. Non-uniform distribution of fibers was observed in the structure of destroyed concrete specimens, and in some zones, clumped fibers. Concrete mixtures with PF were more prone to fiber balling at mixing and molding. Additionally, examination of the specimens' destruction nature indicated poorer adhesion of PF with cement matrix, resulting in specimens' failure due to individual fibers withdrawal. These disadvantages were not observed when using BF for hybrid fiber reinforcement.

$\mathrm{BF}$ is closer to the concrete matrix than PF from the viewpoint of density and elastic characteristics. Therefore, at an optimum ratio with SF it forms a kind of bearing frame that holds the SF, prevents mixture segregation and yields uniform fiber distribution in the concrete structure. All this, in turn, affects the strength characteristics of HFRC. The results obtained in this study add valuable data. Li et al. [16] also have analyzed in detail the mechanical properties of HFRC, which included SF, BF, and PF. Their results showed that mixing BF and SF yield a better synergistic effect than for PF and SF.

\subsection{Influence of Composition Factors on HFRC Strength}

The obtained experimental results demonstrate the possibility of improving the structure and the properties of HFRC using BF. More detailed research was carried out to study the influence of water-cement ratio, cement content, $\mathrm{SF}$ and $\mathrm{BF}$ content and volume ratio on fine-grained HFRC strength. With this aim, a three-level four-factor $B_{4}$-type experiment plan was used [20]. Tables 4 and 5, respectively, present the conditions of experiment planning and the obtained results. 
Table 3. Strength of concrete specimens with different SF and PF contents.

\begin{tabular}{|c|c|c|c|c|c|}
\hline $\mathrm{SF}, \mathrm{kg} / \mathrm{m}^{3}$ & $\mathrm{PF}, \mathrm{kg} / \mathrm{m}^{3}$ & $\begin{array}{c}\text { Total Fibers } \\
\text { Content by Volume, } \\
\mu, \%\end{array}$ & $\begin{array}{l}\text { PF Part in the } \\
\text { Fiber Volume, } \\
n\end{array}$ & $\begin{array}{c}\text { Compressive } \\
\text { Strength at } 7 \text { Days } \\
f_{c m}{ }^{7}, \\
\mathrm{MPa}\end{array}$ & $\begin{array}{c}\text { Flexural Tensile } \\
\text { Strength at } 7 \text { Days } \\
f_{c, t f}{ }^{7}, \\
\text { MPa }\end{array}$ \\
\hline \multicolumn{6}{|c|}{$\mathrm{PF}(l=12 \mathrm{~mm})$} \\
\hline \multirow{3}{*}{80} & 0 & 1.03 & 0.00 & 64.5 & 10.3 \\
\hline & 1 & 1.14 & 0.10 & 64.2 & 10.1 \\
\hline & 2 & 1.25 & 0.18 & 64.6 & 9.4 \\
\hline \multirow{3}{*}{120} & 0 & 1.54 & 0.00 & 66.8 & 13.3 \\
\hline & 1 & 1.65 & 0.07 & 67.2 & 12.7 \\
\hline & 2 & 1.76 & 0.13 & 67.3 & 12.1 \\
\hline \multicolumn{6}{|c|}{$\mathrm{PF}(l=18 \mathrm{~mm})$} \\
\hline \multirow{3}{*}{80} & 0 & 1.03 & 0.00 & 64.5 & 10.3 \\
\hline & 1 & 1.14 & 0.03 & 63.2 & 9.8 \\
\hline & 2 & 1.25 & 0.06 & 62.9 & 8.6 \\
\hline \multirow{3}{*}{120} & 0 & 1.54 & 0.00 & 66.8 & 13.3 \\
\hline & 1 & 1.65 & 0.07 & 65.3 & 10.6 \\
\hline & 2 & 1.76 & 0.13 & 65.9 & 7.8 \\
\hline
\end{tabular}

Table 4. Experiment planning conditions for obtaining HFRC compositions.

\begin{tabular}{|c|c|c|c|c|c|c|}
\hline \multirow{2}{*}{ No. } & \multicolumn{2}{|r|}{ Factors } & \multicolumn{3}{|c|}{ Variation Levels } & \multirow{2}{*}{$\begin{array}{c}\text { Variation } \\
\text { Interval }\end{array}$} \\
\hline & Code & Natural Value & -1 & 0 & +1 & \\
\hline 1 & $X_{1}$ & Cement content, $\mathrm{kg} / \mathrm{m}^{3}(\mathrm{C})$ & 450 & 500 & 550 & 50 \\
\hline 2 & $X_{2}$ & $\mathrm{~W} / \mathrm{C}$ & 0.3 & 0.35 & 0.4 & 0.05 \\
\hline 3 & $X_{3}$ & $\mathrm{SF}, \mathrm{kg} / \mathrm{m}^{3}$ & 80 & 100 & 120 & 20 \\
\hline 4 & $X_{4}$ & $\mathrm{BF}, \mathrm{kg} / \mathrm{m}^{3}$ & 0 & 2 & 4 & 2 \\
\hline
\end{tabular}

The experimental data were processed and analyzed statistically. As a result, corresponding mathematical models of HFRC compressive and flexural tensile strength were obtained (Table 6). Following this table, the obtained models have a form of polynomial regression equations. Those models were used for obtaining graphs and response surfaces of two investigated parameters vs. the influence factors (Figures 4 and 5). In order to obtain these graphs, two factors that are not shown in each of the graphs were fixed at zero level (Table 4).

Following the experimental-statistical models, water-cement ratio, $\left(x_{2}\right)$ is the dominant factor for compressive strength. Decreasing it from +1 to -1 (from W/C $=0.4$ to $\mathrm{W} / \mathrm{C}=0.3$ ) yields a corresponding strength increase of $40 \%$. Moreover, the increase is observed at different cement contents and at different concrete ages. Following Figure 4, this factor has a linear effect in the selected variation range, which is about $70 \%$ of all factors that were considered. Higher cement content $\left(x_{1}\right)$ within the variation limits yields correspondingly higher compressive strength (by $8-20 \%$ ). If the water-cement ratio is constant, varying the SF content $\left(x_{3}\right)$ has a negligible effect on concrete strength. However, following Figure 5, BF $\left(x_{4}\right)$ can yield higher concrete strength at 28 days. This is also indicated by the values of linear coefficients in the regression equations ( -0.1 for $x_{3}$ and 1.0 for $x_{4}$ ). In the authors' opinion, the different effect of hybrid SF and BF on concrete strength is due to higher specific surface of the hybrid fiber and correspondingly higher adhesion with the concrete matrix. 
Table 5. Experimental results on parameters of HFRC compositions.

\begin{tabular}{|c|c|c|c|c|c|c|c|c|c|c|c|c|c|c|c|c|c|c|}
\hline \multirow{2}{*}{ No - } & \multicolumn{4}{|c|}{ Coded Factors Values } & \multicolumn{6}{|c|}{ Components Content, kg/m ${ }^{3}$} & \multirow{2}{*}{ W/C } & \multirow{2}{*}{$\begin{array}{l}\text { SP, } \\
\%\end{array}$} & \multirow{2}{*}{$\begin{array}{l}f_{c m}{ }^{1} \\
\text { MPa }\end{array}$} & \multirow{2}{*}{$\begin{array}{l}f_{c, t f^{1}} \\
\text { MPa }\end{array}$} & \multirow{2}{*}{$\begin{array}{l}f_{c m}{ }^{7} \\
\text { MPa }\end{array}$} & \multirow{2}{*}{$\begin{array}{l}f_{c, t f^{7}} \\
\mathbf{M P a}\end{array}$} & \multirow{2}{*}{$\begin{array}{l}f_{c m}{ }^{28} \\
\mathrm{MPa}\end{array}$} & \multirow{2}{*}{$\begin{array}{c}f_{c, t f^{28}} \\
\mathbf{M P a}\end{array}$} \\
\hline & $X_{1}$ & $X_{2}$ & $X_{3}$ & $X_{4}$ & $C$ & $S$ & CS & $\mathbf{W}$ & SF & BF & & & & & & & & \\
\hline 1 & + & + & + & + & 550 & 732 & 895 & 220 & 120 & 4 & 0.4 & 0.25 & 27.4 & 7.1 & 55.2 & 14.2 & 64.9 & 16.7 \\
\hline 2 & + & + & + & - & 550 & 732 & 895 & 220 & 120 & 0 & 0.4 & 0.20 & 28.6 & 6.2 & 54.7 & 11.1 & 67.2 & 13.8 \\
\hline 3 & + & + & - & + & 550 & 732 & 895 & 220 & 80 & 4 & 0.4 & 0.13 & 30.2 & 6.3 & 57.1 & 12.4 & 67.3 & 12.1 \\
\hline 4 & + & + & - & - & 550 & 732 & 895 & 220 & 80 & 0 & 0.4 & 0.05 & 28.2 & 5.0 & 55.8 & 10.0 & 66.6 & 9.0 \\
\hline 5 & + & - & + & + & 550 & 799 & 977 & 165 & 120 & 4 & 0.3 & 1.18 & 40.5 & 9.4 & 76.9 & 17.9 & 95.9 & 20.9 \\
\hline 6 & + & - & + & - & 550 & 799 & 977 & 165 & 120 & 0 & 0.3 & 1.10 & 40.9 & 8.8 & 78.1 & 15.9 & 96.0 & 19.9 \\
\hline 7 & + & - & - & + & 550 & 799 & 977 & 165 & 80 & 4 & 0.3 & 0.87 & 41.6 & 8.9 & 80.3 & 18.3 & 96.4 & 17.8 \\
\hline 8 & + & - & - & - & 550 & 799 & 977 & 165 & 80 & 0 & 0.3 & 0.80 & 40.3 & 7.7 & 79.7 & 15.5 & 95.2 & 15.2 \\
\hline 9 & - & + & + & + & 450 & 820 & 1002 & 180 & 120 & 4 & 0.4 & 0.44 & 24.1 & 7.2 & 49.2 & 15.2 & 55.9 & 16.2 \\
\hline 10 & - & + & + & - & 450 & 820 & 1002 & 180 & 120 & 0 & 0.4 & 0.40 & 23.8 & 6.6 & 49.1 & 13.9 & 57.3 & 14.9 \\
\hline 11 & - & + & - & + & 450 & 820 & 1002 & 180 & 80 & 4 & 0.4 & 0.26 & 24.5 & 6.1 & 49.6 & 10.8 & 57.1 & 11.4 \\
\hline 12 & - & + & - & - & 450 & 820 & 1002 & 180 & 80 & 0 & 0.4 & 0.20 & 23.0 & 5.2 & 48.0 & 8.2 & 56.9 & 9.5 \\
\hline 13 & - & - & + & + & 450 & 875 & 1069 & 135 & 120 & 4 & 0.3 & 1.14 & 33.9 & 8.3 & 69.9 & 16.9 & 83.8 & 19.8 \\
\hline 14 & - & - & + & - & 450 & 875 & 1069 & 135 & 120 & 0 & 0.3 & 1.05 & 34.1 & 7.5 & 71.0 & 15.2 & 83.9 & 17.0 \\
\hline 15 & - & - & - & + & 450 & 875 & 1069 & 135 & 80 & 4 & 0.3 & 0.34 & 34.3 & 7.2 & 72.2 & 12.8 & 84.8 & 13.7 \\
\hline 16 & - & - & - & - & 450 & 875 & 1069 & 135 & 80 & 0 & 0.3 & 1.00 & 33.8 & 6.3 & 70.4 & 10.3 & 83.3 & 11.8 \\
\hline 17 & + & 0 & 0 & 0 & 550 & 766 & 936 & 193 & 100 & 2 & 0.35 & 0.48 & 32.3 & 8.3 & 67.1 & 16.9 & 79.9 & 19.2 \\
\hline 18 & - & 0 & 0 & 0 & 450 & 847 & 1036 & 158 & 100 & 2 & 0.35 & 0.32 & 29.9 & 7.6 & 64.2 & 15.6 & 75.1 & 18.3 \\
\hline 19 & 0 & + & 0 & 0 & 500 & 776 & 948 & 200 & 100 & 2 & 0.4 & 0.33 & 24.2 & 7.7 & 53.0 & 14.7 & 65.0 & 16.3 \\
\hline 20 & 0 & - & 0 & 0 & 500 & 837 & 1023 & 150 & 100 & 2 & 0.3 & 0.56 & 39.5 & 8.8 & 77.9 & 17.4 & 92.9 & 20.1 \\
\hline 21 & 0 & 0 & + & 0 & 500 & 806 & 986 & 175 & 120 & 2 & 0.35 & 0.34 & 31.7 & 7.5 & 68.1 & 14.2 & 77.2 & 16.4 \\
\hline 22 & 0 & 0 & - & 0 & 500 & 806 & 986 & 175 & 80 & 2 & 0.35 & 0.13 & 32.3 & 6.8 & 62.3 & 11.5 & 78.5 & 12.1 \\
\hline 23 & 0 & 0 & 0 & + & 500 & 806 & 986 & 175 & 100 & 4 & 0.35 & 0.27 & 32.0 & 8.7 & 65.2 & 15.7 & 76.4 & 18.9 \\
\hline 24 & 0 & 0 & 0 & - & 500 & 806 & 986 & 175 & 100 & 0 & 0.35 & 0.20 & 31.6 & 7.5 & 66.0 & 14.6 & 78.1 & 17.1 \\
\hline
\end{tabular}

Table 6. Mathematical models for HFRC strength parameters.

\begin{tabular}{|c|c|c|}
\hline Output Parameter & & Mathematical Models \\
\hline \multirow{3}{*}{ Compressive strength at } & 1 day & $\begin{aligned} f_{c m}^{1}=31.7+2.7 X_{1}- & 5.8 X_{2}-0.2 X_{3}+0.2 X_{4}-0.6 X_{1}^{2}+0.1 X_{2}^{2}+0.3 X_{3}^{2}- \\
& 0.5 X_{1} X_{2}-0.3 X_{1} X_{3}-0.4 X_{3} X_{4}\end{aligned}$ \\
\hline & 7 days & $\begin{aligned} f_{c m}^{7}= & 66.1+3.6 X_{1}-11.3 X_{2}-0.2 X_{3}+0.2 X_{4}-0.7 X_{2}^{2}-2.4 X_{4}^{2}- \\
& 0.4 X_{1} X_{2}-0.5 X_{1} X_{3}+0.2 X_{2} X_{3}+0.3 X_{2} X_{4}-0.4 X_{3} X_{4}\end{aligned}$ \\
\hline & 28 days & $\begin{array}{c}f_{c m}^{28}=78.4+5 X_{1}-14.2 X_{2}-0.1 X_{3}+X_{4}-1.1 X_{1}^{2}-0.6 X_{2}^{2}-0.7 X_{3}^{2}-1.3 X_{4}^{2} \\
-0.1 X_{1} X_{2}+0.2 X_{1} X_{3}-0.35 X_{2} X_{3}\end{array}$ \\
\hline \multirow{3}{*}{ Flexural tensile strength at } & 1 day & $\begin{array}{c}f_{c, t f}^{1}=7.47+0.31 X_{1}-0.82 X_{2}+0.46 X_{3}+0.43 X_{4}-0.18 X_{1}^{2}-0.33 X_{3}^{2}+ \\
0.12 X_{4}^{2}-0.36 X_{1} X_{2}-0.1 X_{1} X_{4}-0.1 X_{3} X_{4}\end{array}$ \\
\hline & 7 days & $\begin{array}{c}f_{c, t f}{ }^{7}=15.56+0.74 X_{1}-1.66 X_{2}+1.38 X_{3}+1.1 X_{4}+0.67 X_{1}^{2}+ \\
0.47 X_{2}{ }^{2}-1.43 X_{3}^{2}-0.43 X_{4}^{2}-0.8 X_{1} X_{2}-X_{1} X_{3}+0.14 X_{1} X_{4}+0.25 X_{2} X_{3}- \\
0.14 X_{3} X_{4}\end{array}$ \\
\hline & 28 days & $\begin{aligned} f_{c, t f}{ }^{28}= & 17.85+0.66 X_{1}-2.03 X_{2}+2.32 X_{3}+X_{4}+0.88 X_{1}^{2}+0.33 X_{2}^{2}-1.62 X_{3}^{2} \\
& -0.57 X_{4}^{2}-0.75 X_{1} X_{2}-0.18 X_{1} X_{3}-0.1 X_{1} X_{4}-0.19 X_{3} X_{4}\end{aligned}$ \\
\hline Melflux 2651Fcontent & & $\begin{array}{c}S P=0.41+0.095 X_{1}-0.33 X_{2}+0.12 X_{3}+0.11 X_{4}-0.06 X_{1}^{2}+ \\
0.2 X_{2}^{2}-0.03 X_{3}^{2}-0.02 X_{4}^{2}-0.07 X_{1} X_{2}-0.02 X_{1} X_{3}+0.04 X_{1} X_{4}-0.05 X_{2} X_{3}+ \\
0.04 X_{2} X_{4}+0.04 X_{3} X_{4}\end{array}$ \\
\hline
\end{tabular}



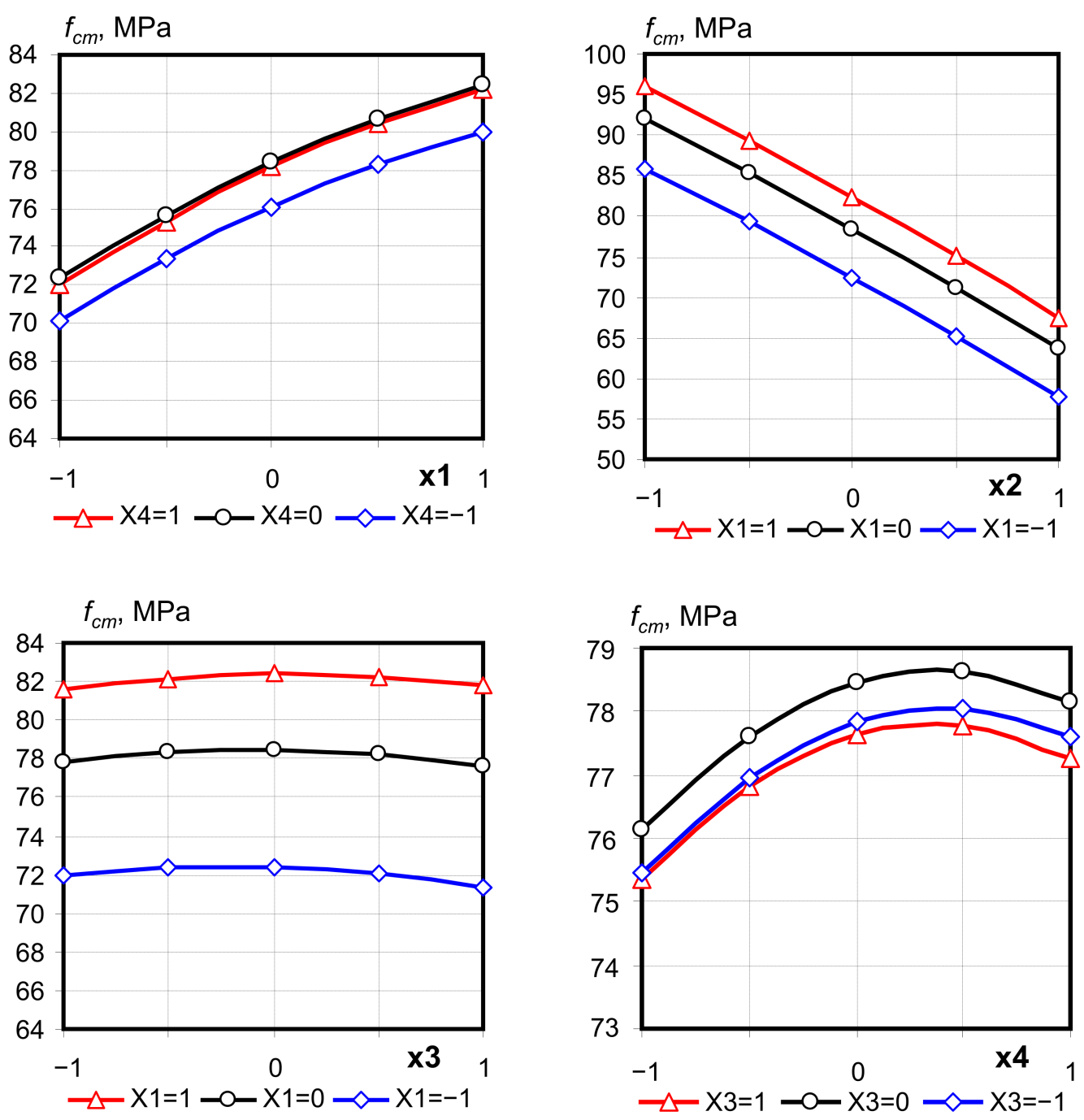

Figure 4. Compressive strength of HFRC at 28 days vs. cement content $\left(x_{1}\right), \mathrm{W} / \mathrm{C}\left(x_{2}\right), \mathrm{SF}\left(x_{3}\right)$ and BF $\left(x_{4}\right)$.

Mathematical models for strength parameters of fine-grained HFRC are presented in Table 6. Based on the effect on compressive strength, the factors can be placed in the following sequence: $x_{2}>x_{1}>x_{4}>x_{3}$. The effect on the concrete flexural strength are different as can be observed in Table 6. For the flexural strength, the SF content $\left(x_{3}\right)$ is one of the most important factors. The highest effect of this factor is evident at 28 days (38\% of all factors influence). W/C is the second by its influence on flexural tensile strength (33\%), and at an early age its influence is higher, compared to SF content (Figure 6).

Following Figure 6 , adding $4 \mathrm{~kg} / \mathrm{m}^{3}$ of BF $\left(x_{4}\right)$ into concrete mixture increases the flexural tensile strength more than $20 \%$ at 1 day, relative to compositions without fiber. This effect is similar to that of SF $\left(x_{3}\right)$. However, as the age increased to 28 days, the influence of $x_{4}$ decreased while that of $x_{3}$ increased.

The effect of SF content factor $\left(x_{3}\right)$ has a weakly pronounced extreme nature, which is evident from the corresponding graphical dependence (Figure 7) and quadratic coefficient in the corresponding regression equation (Table 6). Increasing the fiber content from 80 $\left(x_{3}=-1\right)$ to $110\left(x_{3}=0.5\right) \mathrm{kg} / \mathrm{m}^{3}$ leads to higher flexural tensile strength (increase of 30 to $40 \%$ ). Further increase of SF has a negligible effect on HFRC flexural tensile strength. If $\mathrm{W} / \mathrm{C}$ is constant, then the influence of cement content $\left(x_{1}\right)$ on flexural tensile strength is the lowest, as it has the lowest coefficient in the regression equation. The interaction coefficient of factors $x_{1}$ and $x_{2}$ is relatively high. Hence their dependence on the change of the other is significant (Figure 7). 
Response surfaces analysis from the viewpoint of the output parameter $f_{\mathrm{c}, t f}{ }^{28}$ (Figure 8) indicates that for achieving maximum flexural strength values, the value of factor $\mathrm{W} / \mathrm{C}$ $\left(x_{2}\right)$ should be maintained at the lower variation level, while SF $\left(x_{3}\right)$ and BF $\left(x_{4}\right)$ at the top. It is also evident that $f_{c, t f}^{28}>18 \mathrm{MPa}$ can be achieved for a wide range of SF and $\mathrm{BF}$ corresponding to $100-120 \mathrm{~kg} / \mathrm{m}^{3}$ of $\mathrm{SF}$ and $1-4 \mathrm{~kg} / \mathrm{m}^{3}$ of BF.

Analysis of the superplasticizer content effect demonstrates the highest influence of $\mathrm{W} / \mathrm{C}\left(x_{2}\right)$. Following Table 6 , its linear coefficient in the regression equation is significantly higher relative to the two other factors. Higher SF $\left(x_{3}\right)$ and BF $\left(x_{4}\right)$ contents increase the superplasticizer consumption required for obtaining the necessary workability at a potential increase in water demand. If cement content increases from $450\left(x_{1}=-1\right)$ to $500 \mathrm{~kg} / \mathrm{m}^{3}\left(x_{1}=0\right)$, the superplasticizer content increases (1.5 to 2$)$ times. For $x_{1}=0$ and +1 this dependence significantly decreases.

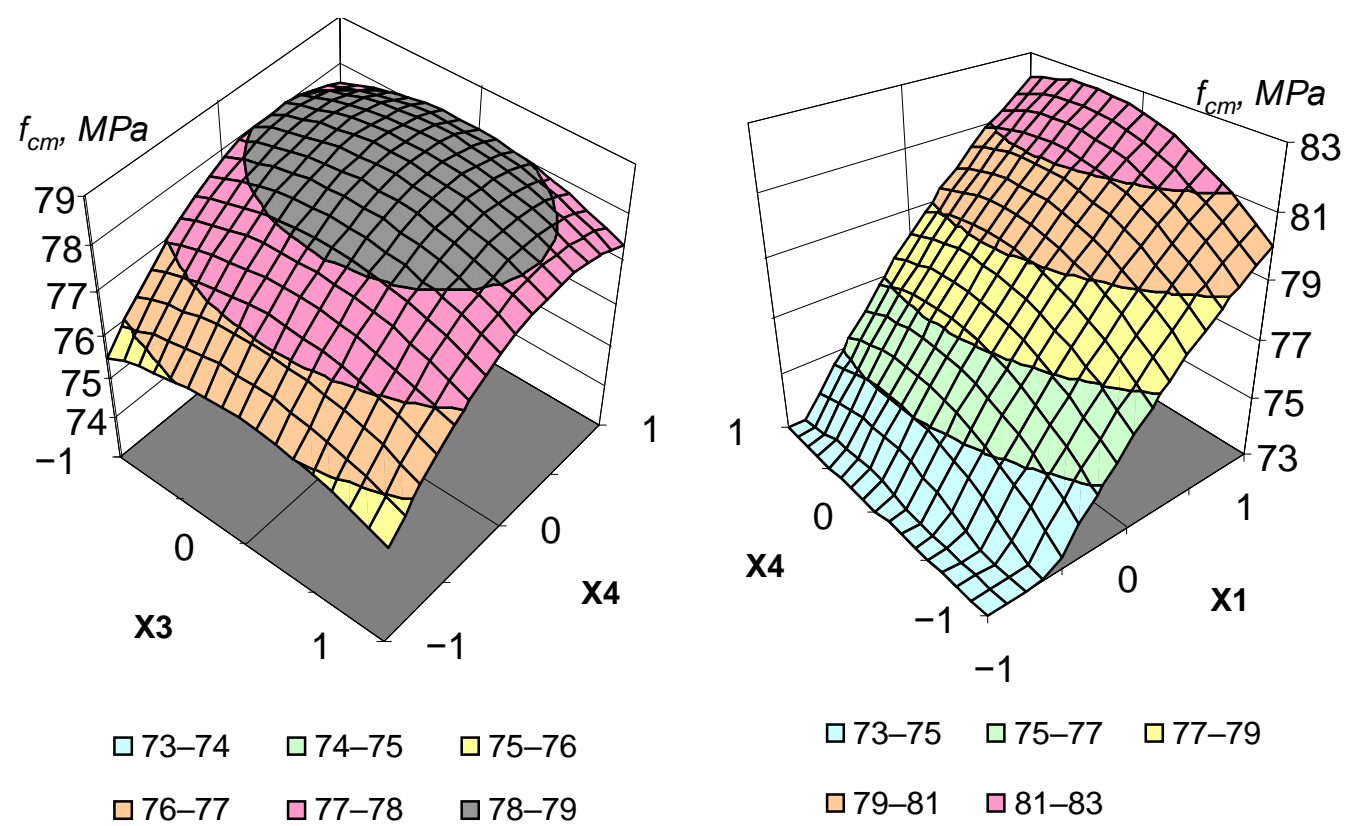

Figure 5. Response surfaces of HFRC compressive strength at 28 days vs. cement content.

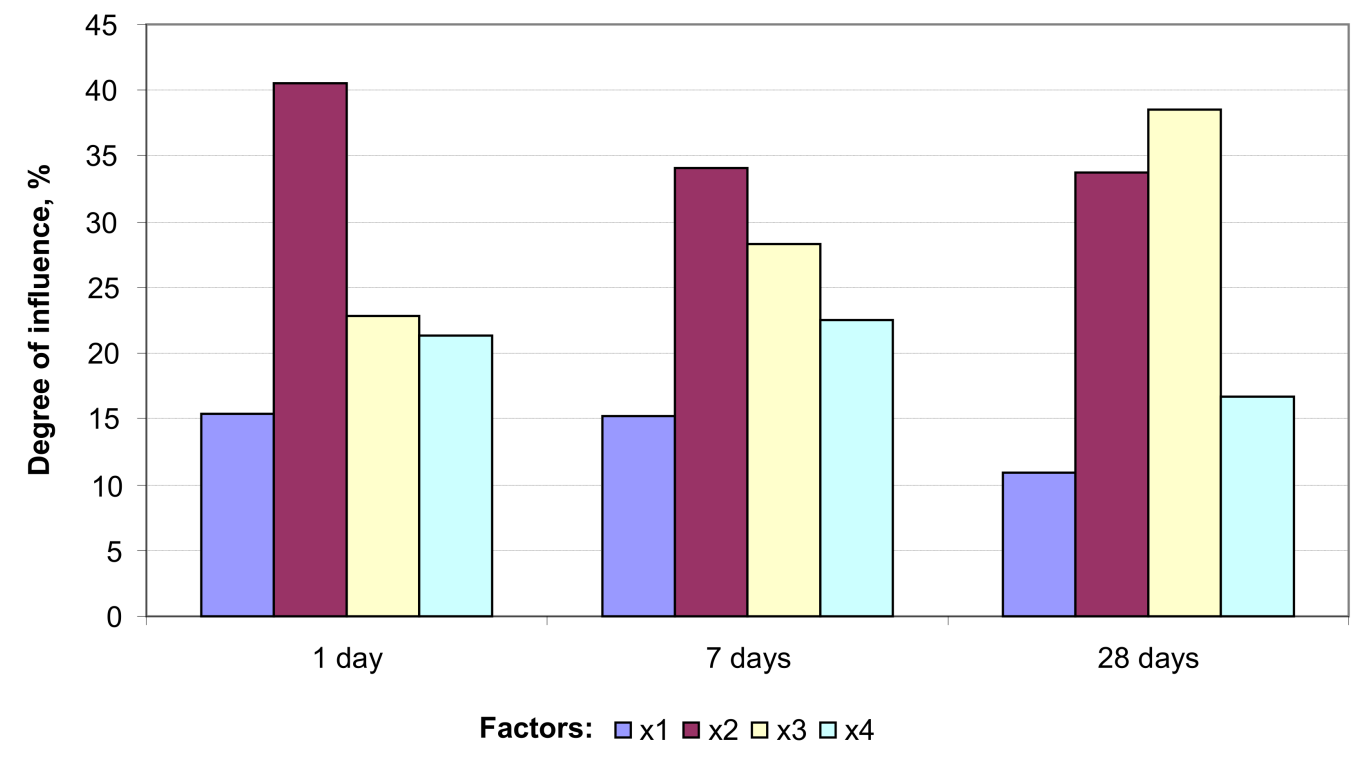

Figure 6. Factors' influence degree on flexural tensile strength at different ages. 

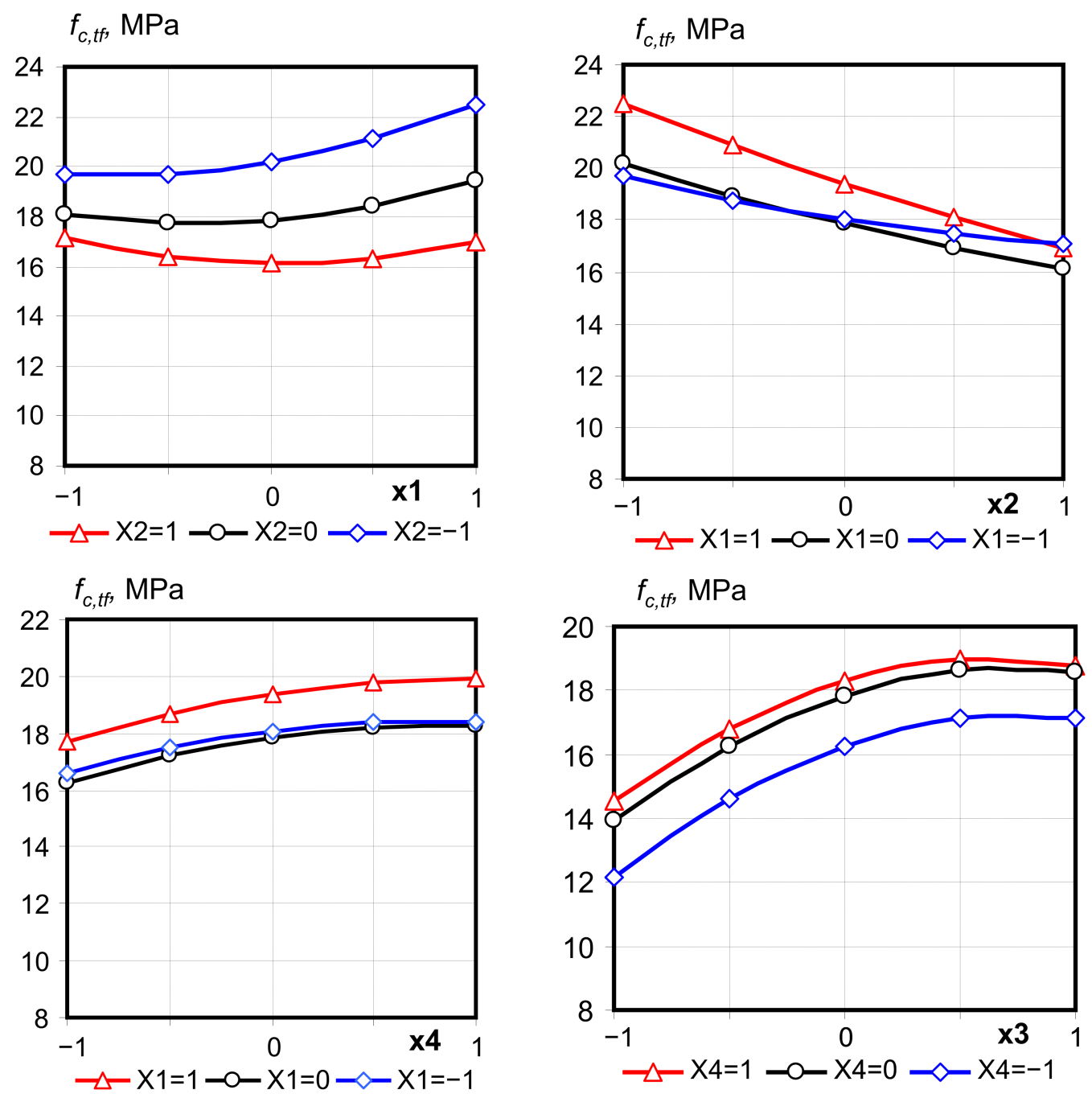

Figure 7. Dependencies of HFRC flexural tensile strength at 28 days on cement content $\left(x_{1}\right), \mathrm{W} / \mathrm{C}$ $\left(x_{2}\right)$, SF content $\left(x_{3}\right)$ and BF content $\left(x_{4}\right)$.

Despite requiring higher water demand which a higher superplasticizer can compensate, the addition of BF improves other properties of the mix and hardened concrete. Results of previous investigations on fine-grained fiber reinforced concrete with compressive strength in the range of 80 to $90 \mathrm{MPa}$ and flexural tensile strength 15 to $18 \mathrm{MPa}$ [23] have demonstrated that optimum SF content is about $100 \mathrm{~kg} / \mathrm{m}^{3}(\mu=1.3 \%)$.

Higher fiber content resulted in lower strength due to concrete segregation. Hybrid BF and SF reinforcement allow increasing the SF content to $120 \mathrm{~kg} / \mathrm{m}^{3}$, fulfilling the requirements of concrete mix structure homogeneity and avoiding segregation. The strength of HFRC increases by 10 to $20 \%$, compared to that with a single SF mixture. 

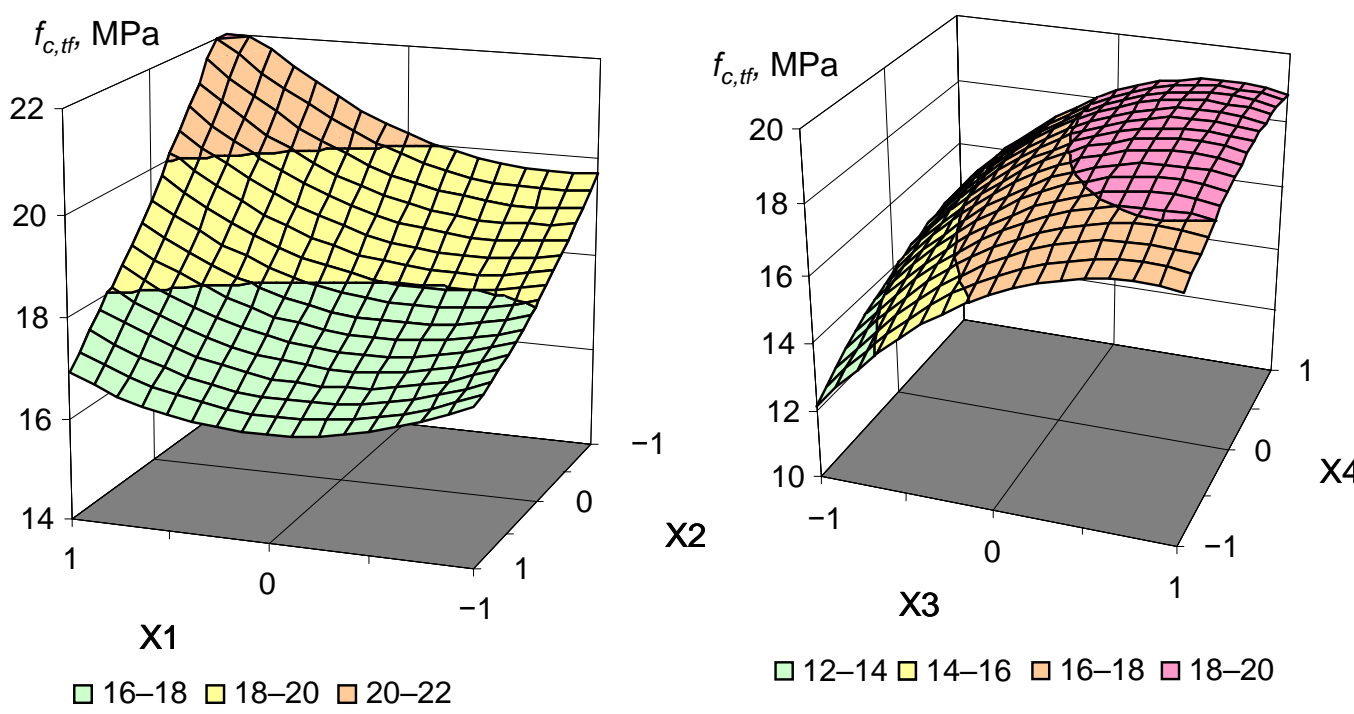

Figure 8. Response surfaces for HFRC flexural tensile strength at 28 days vs. cement content $\left(x_{1}\right)$, $\mathrm{W} / \mathrm{C}\left(x_{2}\right), \mathrm{SF}\left(x_{3}\right)$ and BF $\left(x_{4}\right)$.

\section{Design of HFRC Composition}

Nomograms of the investigated parameters, obtained using experimental-statistical models, allow effective concrete proportioning [20]. A typical control task is aimed at finding combinations of factors that yield the desired values of the output parameter. One of the factors, for example, flexural tensile strength, is selected from the regression equation (Table 6). The regression equation is further solved to find the required values of this factor, and the output parameter's values are obtained. A nomogram for obtaining cement content for a given HFRC flexural tensile strength is presented in Figure 9. The nomogram can be used for the design of HFRC composition with specified features. The dominant parameters of HFRC composition may be SF and BF contents or W/C. When concrete mix proportioning is found following Table 7, the desired HFRC composition range for the required flexural tensile and compressive strength strengths is obtained. Assuming certain fiber contents or W/C using the nomogram in Figure 9, the concrete mix proportioning parameters, yielding the desired flexural tensile strength, are obtained.

The corresponding HFRC mixture parameters in coded form can be obtained as follows:

$$
x_{1}=\frac{\mathrm{C}-500}{50}, x_{2}=\frac{\mathrm{W} / \mathrm{C}-0.35}{0.05}, x_{3}=\frac{\mathrm{SF}-100}{20}, x_{3}=\frac{\mathrm{BF}-2}{2},
$$

where C, BF and SF are cement content, basalt and steel fiber contents, correspondingly.

Substituting the obtained values into the regression equation (Table 6), the desired value of concrete compressive strength at 28 days is obtained. Water demand at a given cement content and $\mathrm{W} / \mathrm{C}$ is:

$$
\mathrm{W}=\mathrm{C} \cdot \mathrm{W} / \mathrm{C},
$$

Substituting the coded values of W/C, cement content and fiber content into the equation (Table 6), corresponding superplasticizer content, yielding the desired concrete mix workability of $13-15 \mathrm{~cm}$, is calculated. If a different concrete mixture workability is required, the superplasticizer content is further specified experimentally. 


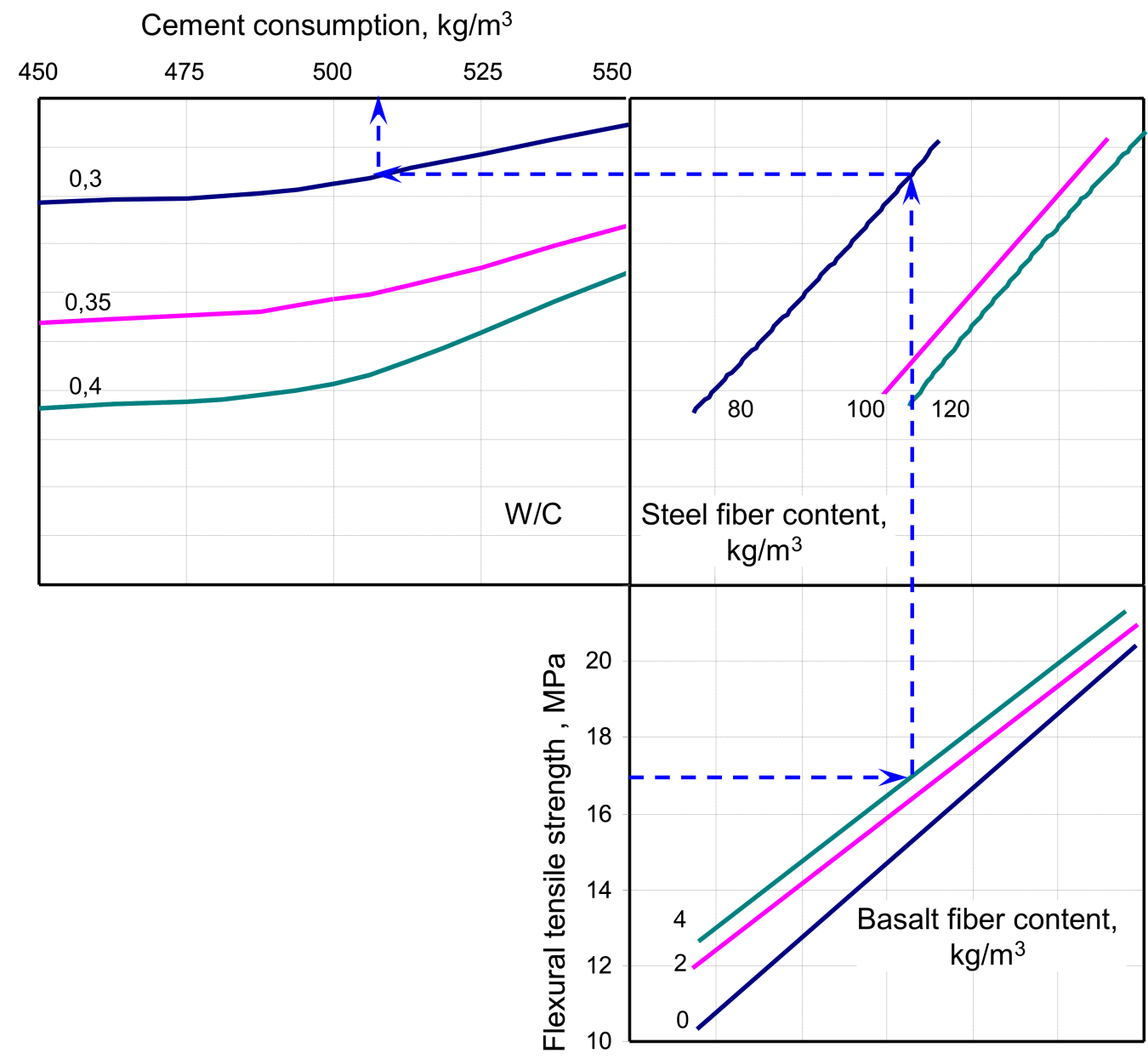

Figure 9. Nomogram for HFRC flexural tensile strength at 28 days.

Table 7. Indicative values of HFRC properties at 28 days.

\begin{tabular}{|c|c|c|c|c|}
\hline $\mathrm{BF}, \mathrm{kg} / \mathrm{m}^{3}$ & $\mathrm{SF}, \mathrm{kg} / \mathrm{m}^{3}$ & W/C & $f_{c, t f^{28}}, \mathrm{MPa}$ & $f_{c m}{ }^{28}, \mathrm{MPa}$ \\
\hline \multirow{4}{*}{$0-2$} & \multirow{2}{*}{ 80-100 } & $0.3-0.35$ & $14.2-17.8$ & $70.3-95.3$ \\
\hline & & $0.35-0.4$ & $10.5-17.8$ & $55.8-81.2$ \\
\hline & \multirow{2}{*}{ 100-120 } & $0.3-0.35$ & $16.7-20.9$ & $68.9-94.4$ \\
\hline & & $0.35-0.4$ & $16.7-18.5$ & $54.2-79.1$ \\
\hline \multirow{4}{*}{$2-4$} & \multirow{2}{*}{ 80-100 } & $0.3-0.35$ & $16.2-20.5$ & $71.1-94.8$ \\
\hline & & $0.35-0.4$ & $12.1-17.2$ & $55.9-82.0$ \\
\hline & \multirow{2}{*}{ 100-120 } & $0.3-0.35$ & $18.2-23.5$ & $69.3-96.3$ \\
\hline & & $0.35-0.4$ & $17.8-18.8$ & $55.8-79.7$ \\
\hline
\end{tabular}

Corresponding contents of aggregates can be found according to the water demand and cement content using Equations (4)-(7) and taking into account that the optimal content of sand is $45 \%$ and that of crushed stone fraction $2-5 \mathrm{~mm}$ by weight is $55 \%$.

The aggregate content in $\mathrm{m}^{3}$ :

$$
V_{A}=1-\left(\frac{\mathrm{C}}{\rho_{C}}+\frac{\mathrm{W}}{\rho_{W}}+\frac{\mathrm{SF}}{\rho_{S F}}+\frac{\mathrm{BF}}{\rho_{B F}}\right)
$$

where $\rho_{C}, \rho_{W}, \rho_{S F}, \rho_{B F}$ (in $\mathrm{kg} / \mathrm{m}^{3}$ ) are the real densities of cement, water, steel and basalt fiber. 
The aggregate weight (crushed stone + sand):

$$
m_{A}=V_{A} \rho_{A}
$$

where $\rho_{A}$ is the real density of aggregate.

The weights of crushed stone and sand are:

$$
\begin{gathered}
m_{C . S}=0.55 m_{A} \\
m_{S}=0.45 m_{A}
\end{gathered}
$$

\section{Numerical Example}

The efficiency of the proposed methodology is demonstrated in a numerical example aimed at the design of fine-grained HFRC composition. The desired values of compressive and flexural tensile strengths of concrete at 28 days are $70 \mathrm{MPa}$ and $17 \mathrm{MPa}$, respectively. The aggregates' mix includes crushed granite stone $2-5 \mathrm{~mm}$ and sand with real density of $2700 \mathrm{~kg} / \mathrm{m}^{3}$. The density of cement is $3100 \mathrm{~kg} / \mathrm{m}^{3}, \mathrm{SF} 7850 \mathrm{~kg} / \mathrm{m}^{3}$ and BF $2700 \mathrm{~kg} / \mathrm{m}^{3}$. The design process includes the following steps:

- $\quad$ Selecting the fiber content and $W / C$ for concrete with given strength values (Table 6). In our case $\mathrm{SF}=80$ to $120 \mathrm{~kg} / \mathrm{m}^{3}, \mathrm{BF}=0$ to $4 \mathrm{~kg} / \mathrm{m}^{3}, \mathrm{~W} / \mathrm{C}=0.3$ to 0.4 ;

- Assuming minimal SF content $\left(80 \mathrm{~kg} / \mathrm{m}^{3}\right)$, the required water-cement ratio and cement content, yielding the desired concrete strengths, are found using the nomogram (blue line in Figure 9);

- Translating the obtained values $\left(\mathrm{W} / \mathrm{C}=0.3, \mathrm{C}=507 \mathrm{~kg} / \mathrm{m}^{3}, \mathrm{SF}=80 \mathrm{~kg} / \mathrm{m}^{3}, \mathrm{BF}=4 \mathrm{~kg} / \mathrm{m}^{3}\right)$ in coded form:

$$
\begin{gathered}
x_{1}=\frac{(\mathrm{C}-500)}{50}=\frac{(507-500)}{50}=0.14, x_{2}=\frac{(\mathrm{W} / \mathrm{C}-0.35)}{0.05}=\frac{(0.3-0.35)}{0.05}=-1 \\
x_{3}=\frac{(\mathrm{SF}-100)}{20}=\frac{(80-100)}{20}=-1, x_{4}=\frac{(\mathrm{BF}-2)}{2}=\frac{(4-2)}{2}=1
\end{gathered}
$$

- Substituting of the coded values in the regression equation (Table 6), calculating the concrete compressive strength

$$
\begin{gathered}
f_{c}=78.4+5 \cdot 0.13-14.2 \cdot(-1)-0.1 \cdot(-1)+1 \cdot 1-1.1 \cdot(0.13)^{2}-0.6 \cdot(-1)^{2}-0.7 \\
(-1)^{2}-1.3 \cdot 1^{2}-0.1 \cdot 0.13 \cdot(-1)+0.2 \cdot 0.13 \cdot(-1)-0.35 \cdot(-1) \cdot(-1)=91.4 \mathrm{MPa} .
\end{gathered}
$$

Verifying if the requirement is satisfied: $91.4 \geq 70 \mathrm{MPa}$

- $\quad$ Calculating the water demand, corresponding to $\mathrm{W} / \mathrm{C}$ and cement content using Equation (3):

$$
\mathrm{W}=\mathrm{C} \cdot \mathrm{W} / \mathrm{C}=507 \cdot 0.3=152 \mathrm{~kg} / \mathrm{m}^{3} .
$$

- Calculating the superplasticizer content for known composition parameters: $\mathrm{SP}=0.93 \%$ of the cement weight.

- $\quad$ Calculating the aggregates content using Equations (4)-(7):

$$
\begin{gathered}
V_{A}=1-\left(\frac{507}{3100}+\frac{152}{1000}+\frac{80}{7850}+\frac{4}{2700}\right)=0.673 \mathrm{~m}^{3} \\
m_{A}=V_{A} \rho_{A}=0.673 \cdot 2700=1817 \mathrm{~kg} / \mathrm{m}^{3} \\
m_{S}=m_{A} \cdot 0.45=1817 \cdot 0.45=818 \mathrm{~kg} / \mathrm{m}^{3}, m_{C . S}=m_{A} \cdot 0.55=1817 \cdot 0.55=999 \mathrm{~kg} / \mathrm{m}^{3}
\end{gathered}
$$

The final concrete proportioning is: $152 \mathrm{~kg} / \mathrm{m}^{3}$ of water, $507 \mathrm{~kg} / \mathrm{m}^{3}$ of cement, $818 \mathrm{~kg} / \mathrm{m}^{3}$ of sand, $999 \mathrm{~kg} / \mathrm{m}^{3}$ of crushed granite stone fraction 2-5 mm. The Melflux $2651 \mathrm{f}$ superplasticizer content is $0.93 \%$ by cement weight, SF and BF contents are $80 \mathrm{~kg} / \mathrm{m}^{3}$ and $4 \mathrm{~kg} / \mathrm{m}^{3}$ correspondingly. This mix design method, like any other concrete mix design method, 
gives a preliminary mix proportion. The calculated values should then be tested and adjusted to get the final mix design values.

\section{Conclusions}

A method for the design of hybrid fiber reinforced concrete was developed. It is based on adapted mathematical experiments planning method. The influence of adding hybrid basalt, steel and polypropylene fiber on fine grained concrete features was investigated. Quantitative dependences for cement content, water-cement ratio, basalt and steel fiber contents and their influence on concrete flexural tensile and compressive strengths were obtained. The effect of Melflux 2651F superplasticizer was also studied.

The results, obtained in the frame of this research demonstrate that using hybrid basalt and steel fiber enables to achieve high performance fine-grained concrete. Using basalt fiber yields concrete flexural tensile strength that are 10 to $20 \%$ higher relative to concrete compositions with single steel fiber or hybrid polypropylene and steel fiber. The obtained results allow proper concrete mixtures proportioning to achieve target workability and strengths.

The experimental-statistical models for compressive and flexural strengths and the superplasticizer content were used for developing a design methodology for hybrid fiber reinforced concrete compositions. This methodology allows finding the optimal values of concrete mix components required for achieving the desired concrete properties. The results of this study show that hybrid SF and BF reinforcement yields further improvement in concrete properties. These results will allow new practical applications of SF and BF reinforced concrete and expand possibilities for using this material in construction.

Author Contributions: Conceptualization, L.D., O.B. and Y.R.; methodology, L.D., O.B. and Y.R.; software, O.B.; validation, L.D., O.B., Y.R. and B.H.T.; formal analysis, O.B.; investigation, O.B.; resources, L.D.; data curation, O.B.; writing-original draft preparation, O.B.; writing-review and editing, L.D., Y.R. and B.H.T.; visualization, O.B.; supervision, L.D.; project administration, L.D. All authors have read and agreed to the published version of the manuscript.

Funding: This research received no external funding.

Institutional Review Board Statement: Not applicable.

Informed Consent Statement: Not applicable.

Data Availability Statement: Data supporting reported results can be found in the manuscript.

Conflicts of Interest: The authors declare no conflict of interest.

\section{References}

1. Shah, A.A.; Ribakov, Y. Recent trends in steel fibered high-strength concrete. Mater. Des. 2011, 32, 4122-4151. [CrossRef]

2. Thomas, J.; Ramaswamy, A. Mechanical Properties of Steel Fiber-Reinforced Concrete. J. Mater. Civ. Eng. 2007, 19, 385-392. [CrossRef]

3. Holschemacher, K.; Mueller, T.; Ribakov, Y. Effect of steel fibres on mechanical properties of high-strength concrete. Mater. Des. 2010, 31, 2604-2615. [CrossRef]

4. Dong, S.; Han, B.; Yu, X.; Ou, J. Dynamic impact behaviors and constitutive model of super-fine stainless wire reinforced reactive powder concrete. Constr. Build. Mater. 2018, 184, 602-616. [CrossRef]

5. Şahin, Y.; Köksal, F. The influences of matrix and steel fibre tensile strengths on the fracture energy of high-strength concrete. Constr. Build. Mater. 2011, 25, 1801-1806. [CrossRef]

6. Suksawang, N.; Wtaife, S.; Alsabbagh, A. Evaluation of Elastic Modulus of Fiber-Reinforced Concrete. ACI Mater. J. 2018, 115. [CrossRef]

7. Iskhakov, I.; Ribakov, Y. Two-layer concrete bridge beams as composite elements. Struct. Concr. 2013, 14, 271-277. [CrossRef]

8. Iskhakov, I.; Ribakov, Y.; Holschemacher, K. Experimental investigation of continuous two-layer reinforced concrete beams. Struct. Concr. 2017, 18, 205-215. [CrossRef]

9. Zorla, E.; Ipbuker, C.; Gulik, V.; Kovaljov, S.; Kiisa, M.; Biland, A.; Tkaczyk, A.H. Optimization of Basalt Fiber in Concrete Composite for Industrial Application in Estonia. Fresenius Environ. Bull. 2016, 25, 355-364.

10. Ayub, T.; Shafiq, N.; Nuruddin, M.F. Mechanical Properties of High-performance Concrete Reinforced with Basalt Fibers. Procedia Eng. 2014, 77, 131-139. [CrossRef] 
11. Ayub, T.; Shafiq, N.; Khan, S.U. Compressive Stress-Strain Behavior of HSFRC Reinforced with Basalt Fibers. J. Mater. Civ. Eng. 2016, 28, 6015014. [CrossRef]

12. Nihal, P.P.; Shinu, S. Experimental Studies on Steel and Basalt Fiber Reinforced Concrete. Int. J. Innov. Res. Sci. Eng. Technol. 2017, 6, 6753-6761.

13. Kumar, M.V.; Niveditha, K.; Anusha, B.; Sudhakar, B. Comparison Study of Basalt Fiber and Steel Fiber as Additives to Concrete. IJRASET 2017, 5, 6-14. [CrossRef]

14. Shaikh, F.U.A.; Taweel, M. Compressive strength and failure behaviour of fibre reinforced concrete at elevated temperatures. Adv. Concr. Constr. 2015, 3, 283-293. [CrossRef]

15. Manu, P.P.; Eldhose, C. Flexural Behavior of Hybrid Steel Basalt Fibre Reinforced Concrete. Int. Res. J. Eng. Technol. 2019, 6, 760-764.

16. Li, Z.-X.; Li, C.-H.; Shi, Y.-D.; Zhou, X.-J. Experimental investigation on mechanical properties of Hybrid Fibre Reinforced Concrete. Constr. Build. Mater. 2017, 157, 930-942. [CrossRef]

17. Chakravarthy, R.; Venkatesan, S.; Patnaikuni, I. Review on Hybrid Fiber Reinforced High Performance High Volume Flyash Concrete. IJSCER 2016, 5, 39-43. [CrossRef]

18. EN 14889-1:2006. Fibres for Concrete-Part 1: Steel Fibres-Definitions, Specifications and Conformity; British Standards Institution: London, UK, 2006.

19. ASTM C78/C78M-18. Standard Test Method for Flexural Strength of Concrete (Using Simple Beam with Third-Point Loading); ASTM International: West Conshohocken, PA, USA, 2018.

20. Dvorkin, L.I.; Dvorkin, O.; Ribakov, Y. Mathematical Experiments Planning in Concrete Technology; Nova Science Publishers: New York, NY, USA, 2012; ISBN 9781621002833.

21. Box, G.E.P.; Hunter, J.S.; Hunter, W.G. Statistics for Experimenters: Design, Innovation, and Discovery, 2nd ed.; Wiley: Hoboken, NJ USA, 2005; ISBN 9780471718130.

22. Han, J.; Zhao, M.; Chen, J.; Lan, X. Effects of steel fiber length and coarse aggregate maximum size on mechanical properties of steel fiber reinforced concrete. Constr. Build. Mater. 2019, 209, 577-591. [CrossRef]

23. Dvorkin, L.; Bordiuzhenko, O.; Zhitkovsky, V.; Marchuk, V. Mathematical modeling of steel fiber reinforced concrete properties and selecting its effective composition. IOP Conf. Ser. Mater. Sci. Eng. 2019, 708, 12085. [CrossRef] 